\title{
COVID-19 vaccine landscape
}

\author{
Seneviratne $\mathbf{S L}^{1,2,3}$, Jayarajah $\mathbf{U}^{2}$, Abeysuriya $\mathbf{V}^{3}$, Rahman $\mathbf{A}^{2}$, Wanigasuriya $\mathbf{K}^{4}$ \\ Journal of the Ceylon College of Physicians, 2020, 51, 120-131
}

\begin{abstract}
Coronavirus disease 2019 (COVID-19) is caused by severe acute respiratory syndrome coronavirus 2 (SARS-CoV-2). It is currently pandemic, and as of 15th November 2020, there have been 53.7 million confirmed cases worldwide and around 1.3 million deaths. The availability of an effective vaccine is the best long-term answer to the current COVID-19 pandemic. More than 210 candidate vaccines have come into development since the start of the pandemic. Eleven vaccines (ten of them specifically directed against SARS-CoV-2) have entered phase 3 clinical trials. Five of these vaccines have also been approved for early or limited use. This review outlines information on the current COVID-19 vaccine pipeline, discusses the pros and cons of different vaccine delivery systems and the steps involved in getting a safe and effective vaccine to the global population.
\end{abstract}

Key words: COVID-19, vaccine, SARS-CoV-2, Coronavirus, Coronavirus disease 2019, Severe acute respiratory syndrome coronavirus 2 , pandemic

\section{Introduction}

Coronavirus disease 2019 (COVID-19) is caused by severe acute respiratory syndrome coronavirus 2 (SARS-CoV-2). ${ }^{1}$ This virus originated in Wuhan, China in December 2019. ${ }^{2}$ It is currently pandemic, and as of 15 th November 2020, there have been more than 53 million cases worldwide and over 1.3 million deaths. ${ }^{3}$
COVID-19 causes harm in three broad ways: death or long-term organ damage, constrains on the operation of effective healthcare systems and adverse effects on national/regional economies. ${ }^{4-8}$ The availability of an effective vaccine is the best long-term answer to the current COVID-19 pandemic. ${ }^{9,10}$ There has been an international response to COVID-19 vaccine development. More than 210 candidate vaccines have come into development since the start of the pandemic. Eleven vaccines (ten of them specifically directed against SARS-CoV-2) have entered phase 3 clinical trials (Table 1). Five of these vaccines have also been approved for early or limited use. In this review, we have described the different COVID-19 vaccine candidates, their mechanism of action and the human clinical trial findings published so far.

\section{Vaccine development cycle}

Vaccine development occurs in several stages known as the vaccine development cycle (Figure 1). This includes: preclinical, clinical (phase I, II and III) and the manufacturing (phase IV) stages. In the preclinical stage, the vaccine target is identified and assessed for feasibility and safety by means of in vivo and animal studies. During the clinical stages, safety, immunogenicity and efficacy are assessed in a step wise manner using increasing numbers of individuals. At the end of phase III, the properties of the vaccine and administration protocols would be defined and it should be suitable for large scale manufacturing. During Phase IV, comparative clinical studies and postmarketing surveillance should take place. In general,

\footnotetext{
${ }^{1}$ Institute of Infection and Immunity, Royal Free Hospital and University College London, London, UK, ${ }^{2}$ Department of Surgery, Faculty of Medicine, University of Colombo, Sri Lanka, ${ }^{3}$ Nawaloka Hospital Research and Education Foundation, Nawaloka Hospitals PLC, Colombo, Sri Lanka, ${ }^{4}$ Department of Medicine, Faculty of Medicine, University of Sri Jayewardenepura, Sri Lanka.
}

Correspondence: SLS, e-mail: suran200@yahoo.co.uk

https://orcid.org/0000-0002-6548-5673

Received 16 November 2020, accepted 28 November 2020.

This is an open-access article distributed under the terms of the Creative Commons Attribution License, which permits unrestricted use, distribution, and reproduction in any medium, provided the original author and source are credited. 
Table 1. Vaccines that have entered Phase 3 Trials

\begin{tabular}{|c|c|c|c|}
\hline Class of vaccine & Vaccine candidate & Developer & Vaccine platform \\
\hline Genetic vaccines & $\begin{array}{l}\text { mRNA-1273 } \\
\text { BNT162 }\end{array}$ & $\begin{array}{l}\text { Moderna/NIAID } \\
\text { BioNTech/Fosun } \\
\text { Pharma/Pfizer }\end{array}$ & $\begin{array}{l}\text { LNP-encapsulated mRNA } \\
\text { Three LNP-mRNAs }\end{array}$ \\
\hline \multirow[t]{4}{*}{ Viral vector vaccines } & Ad5-nCov & $\begin{array}{l}\text { CanSino Biological Inc/ } \\
\text { Beijing Institute of } \\
\text { Biotechnology }\end{array}$ & Non-replicating viral vector \\
\hline & $\begin{array}{l}\text { AZD1222 (formerly } \\
\text { ChAdOx1 nCov-19 }\end{array}$ & University of Oxford/Astra Zeneca & Non-replicating viral vector \\
\hline & $\begin{array}{l}\text { Adeno-based } \\
\text { (rAd26-S+rAd5-S) }\end{array}$ & Gamaleya Research Institute & Non-replicating viral vector \\
\hline & Ad26COVS1 & Janssen Pharmaceutical Company & Non-replicating viral vector \\
\hline Protein based vaccines & Protein subunit & Novavax & $\begin{array}{l}\text { Full length rSARS-CoV-2 } \\
\text { glycoprotein nanoparticle } \\
\text { vaccine adjuvanted with } \\
\text { Matrix M }\end{array}$ \\
\hline \multirow[t]{3}{*}{$\begin{array}{l}\text { Inactivated coronavirus } \\
\text { vaccines }\end{array}$} & Inactivated & $\begin{array}{l}\text { Beijing institute of Biological } \\
\text { Products/SinoPharm }\end{array}$ & Inactivated virus \\
\hline & Inactivated & $\begin{array}{l}\text { Wuhan Institute of Biological } \\
\text { Products / SinoPharm }\end{array}$ & Inactivated virus \\
\hline & Inactivated & Sinovac & Inactivated virus \\
\hline Repurposed vaccines & $\begin{array}{l}\text { Bacillus Calmette- } \\
\text { Guerin (BCG) }\end{array}$ & $\begin{array}{l}\text { Murdoch children's } \\
\text { Research Institute }\end{array}$ & $\begin{array}{l}\text { Attenuated Mycobacterium } \\
\text { bovis }\end{array}$ \\
\hline
\end{tabular}

\section{Stages of vaccine development}

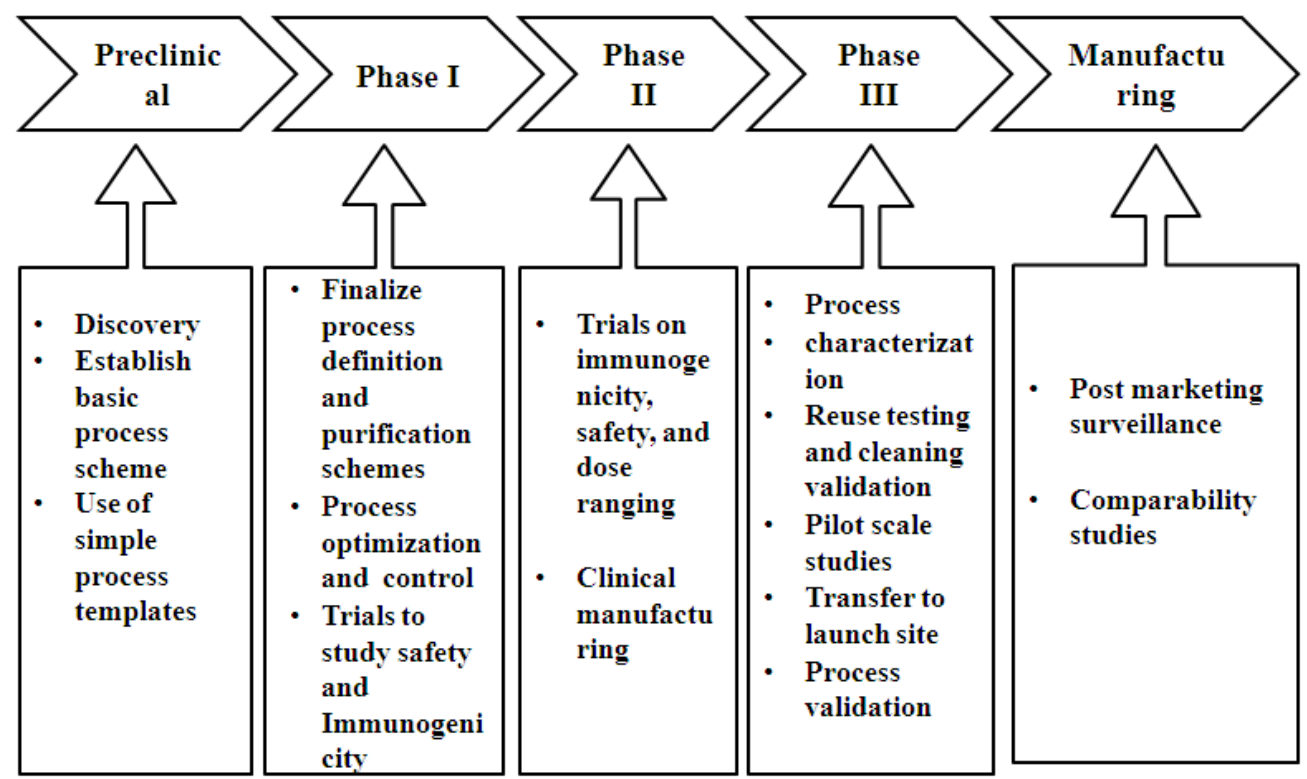

Figure 1. Stages of vaccine development cycle. 
completion of the different stages of vaccine development takes over a decade. However, during pandemic situations such as the COVID-19 pandemic, this process has been significantly shortened (to around one year) because several steps are carried out in parallel rather than sequentially. Prior to this, the shortest time for vaccine development was four years, with the mumps vaccine.

\section{Potential targets for a COVID-19 vaccine}

SARS-CoV- 2 is an enveloped $\beta$ coronavirus. ${ }^{11}$ The viral envelope consists of the spike (S) glycoprotein and the envelope $(\mathrm{E})$ and membrane $(\mathrm{M})$ proteins (Figure 2). The $S$ glycoprotein mediates host cell attachment and is required for viral entry. It consists of two subunits; S1 and S2 (Figure 3). The S1 subunit is responsible for attachment to the ACE receptor present on host cells and S2 for the subsequent fusion of the cell membranes of both virus and the host. ${ }^{12}$ The S1 subunit has a receptor-binding domain (RBD). The $S$ protein has been identified as the major immunogenic target for vaccine development. ${ }^{13}$ Most of the COVID-19 vaccines in development are intended to induce antibody responses that neutralise SARS-CoV-2. The expectation is that this would

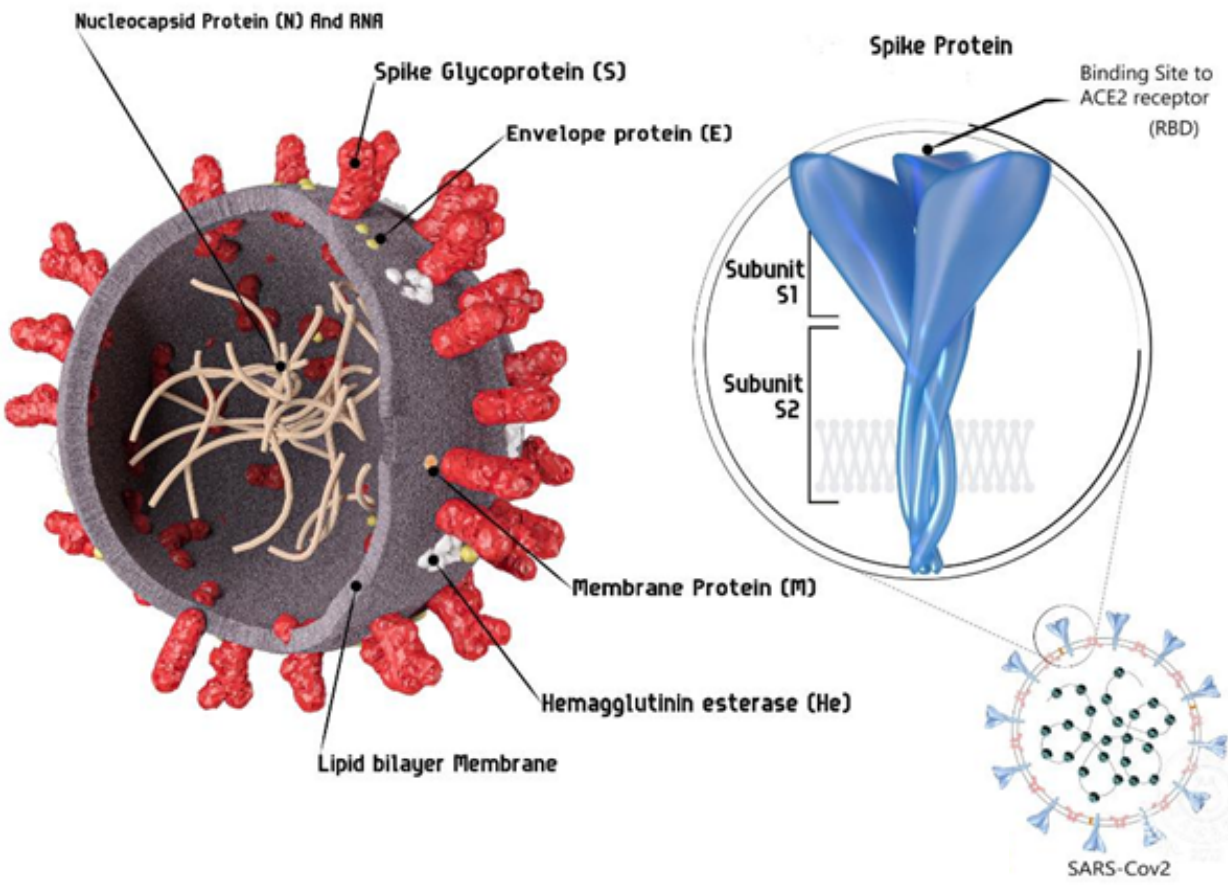

Figure 2. Structure of SARS-CoV-2 virus.

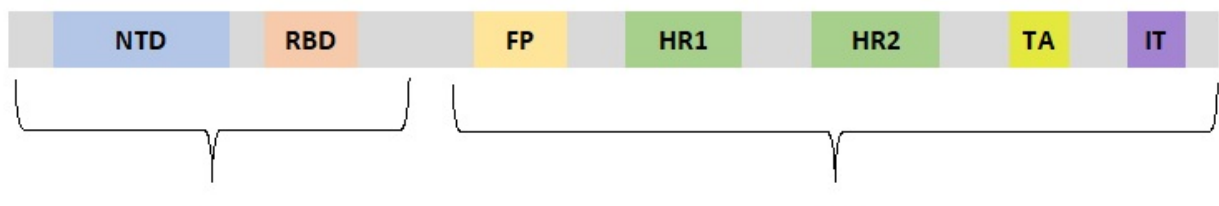

S1

NTD: N-Terminal Domain

RBD: Receptor Binding Domain
FP: Fusion Protein

HR1: Heptad Repeat 1

HR2: Heptad Repeat 2

TA: Transmembrane anchor

IT: Intracellular Tail

Figure 3. SARS-CoV-2 Spike glycoprotein 
prevent the virus from entering target cells and infecting the host. In some cases, the vaccines may also induce antibody and/or cellular immune responses that can kill and eliminate already infected cells. A major driving force behind many of the existing programs appears to be the speed at which a vaccine product can be manufactured at scale using existing production facilities.

\section{Categories of COVID-19 vaccines in development}

The categories of vaccines for protection against SARS-Cov-2 infection and/or disease includes the following: genetic/nucleic acid (mRNA or DNA) vaccines, viral vector (non-replicating or replicating) vaccines, recombinant spike or RBD-protein vaccines, inactivated virus vaccines and live attenuated virus vaccines (Table 2). Some important features of each of these categories are outlined below.

\section{$R N A$ vaccines}

DNA is the genetic code of living structures and proteins are the building blocks. mRNA translates DNA into protein. An mRNA vaccine against COVID-19 would instruct the body's cells to produce specific coronavirus proteins (and not the virus per se). These proteins would then trigger an antibody and cellular immune response. mRNA technology is relatively new (only about 20 years old). Presently, three firms lead the field (two German firms - BioNTech and Curevac and the US biotech company Moderna). ${ }^{14-19}$ BioNTech has teamed up with Pfizer and Fosun from Japan and Curevac and is developing its vaccine with the Centre of Epidemic Preparedness Innovation (CEPI). Two Belgian firms (eTheRNa and Ziphus therapeutics) and Sanofi/Triamtobio have also recently entered this arena.

Normally, it would take around 18 months to design a vaccine and get it to phase 1 testing. This is because complex proteins or inactivated viruses need to be designed, produced and then tested. This time period is shortened with mRNA vaccines. For instance, Moderna took around two months to enter phase 1 trials, after the SARS-CoV-2 viral sequence was released. mRNA vaccines are designed using the sequence of virus. Thus, the lab does not need to work with the virus itself. Industrial production of mRNA is also easier and faster. mRNA consists of simple chains of nucleosides and no complex proteins need to be made. The persons own body cells become factories when mRNA is delivered into cells. mRNA is better than DNA at activating the immune system and has better access to cells. It is safer than the delivery of foreign DNA to an individual and does not carry the risk of integration into the genetic material of the target cell. It could also be directly taken up by cells of the immune system without additional stimulation. However, one needs to remember that no mRNA vaccine or therapeutic has still been approved. Furthermore, the amount of animal data on this aspect is still comparatively small.

Very recently, BioNTech/Pfizer announced their mRNA-based-vaccine candidate BNT162b2 was more than $90 \%$ effective in preventing COVID-19 in participants at seven days after the second dose of vaccine. The study has enrolled 43,538 participants and the first interim efficacy analysis evaluated 94 confirmed COVID-19 cases in the trial participants. No serious safety concerns were announced. Approximately $42 \%$ of the global participants and $30 \%$ of the US participants have racially and ethnically diverse backgrounds. ${ }^{20}$ One needs to remember that the BioNTech/Pfizer vaccine comes with special storage challenges, as it needs to be stored at -70 degrees centigrade. An update earlier this week stated the BNT162b2 vaccine was $94 \%$ effective among adults over the age of 65 years. Moderna also announced the findings of an interim analysis of their phase 3 trial. They found their vaccine candidate mRNA-1273 to be safe and well tolerated and to have a vaccine efficacy of $94.5 \% .^{21}$

\section{DNA vaccines}

With DNA vaccines, double-strand DNA is injected into the recipient (intradermal injection using an electroporation device). ${ }^{22-23}$ It has a better safety profile than live attenuated vaccines. Furthermore, the manufacturing process is well defined and a freezedried formulation is possible. Inovio pharmaceuticals and Cobra biologics have initiated trials with DNA vaccines for COVID-19. In April 2020, Inovio announced the initiation of phase 1 human clinical trials in the US and in June, the trials were extended to South Korea and China. In July 2020, the company announced positive interim data when the vaccine was given to non-human primates. However, at the end of September 2020, the FDA requested more information about the vaccine and its delivery device prior to granting approval for the commencement of the phase $2 / 3$ trial.

\section{Viral and bacterial vector-based vaccines}

Potentially immunogenic parts of the SARS-CoV2 virus may be inserted into a viral or bacterial vector and this could then be used as a vaccine. The common vectors in use at present includes: adenovirus, adenoassociated virus, lentivirus and lactic acid bacteria. 


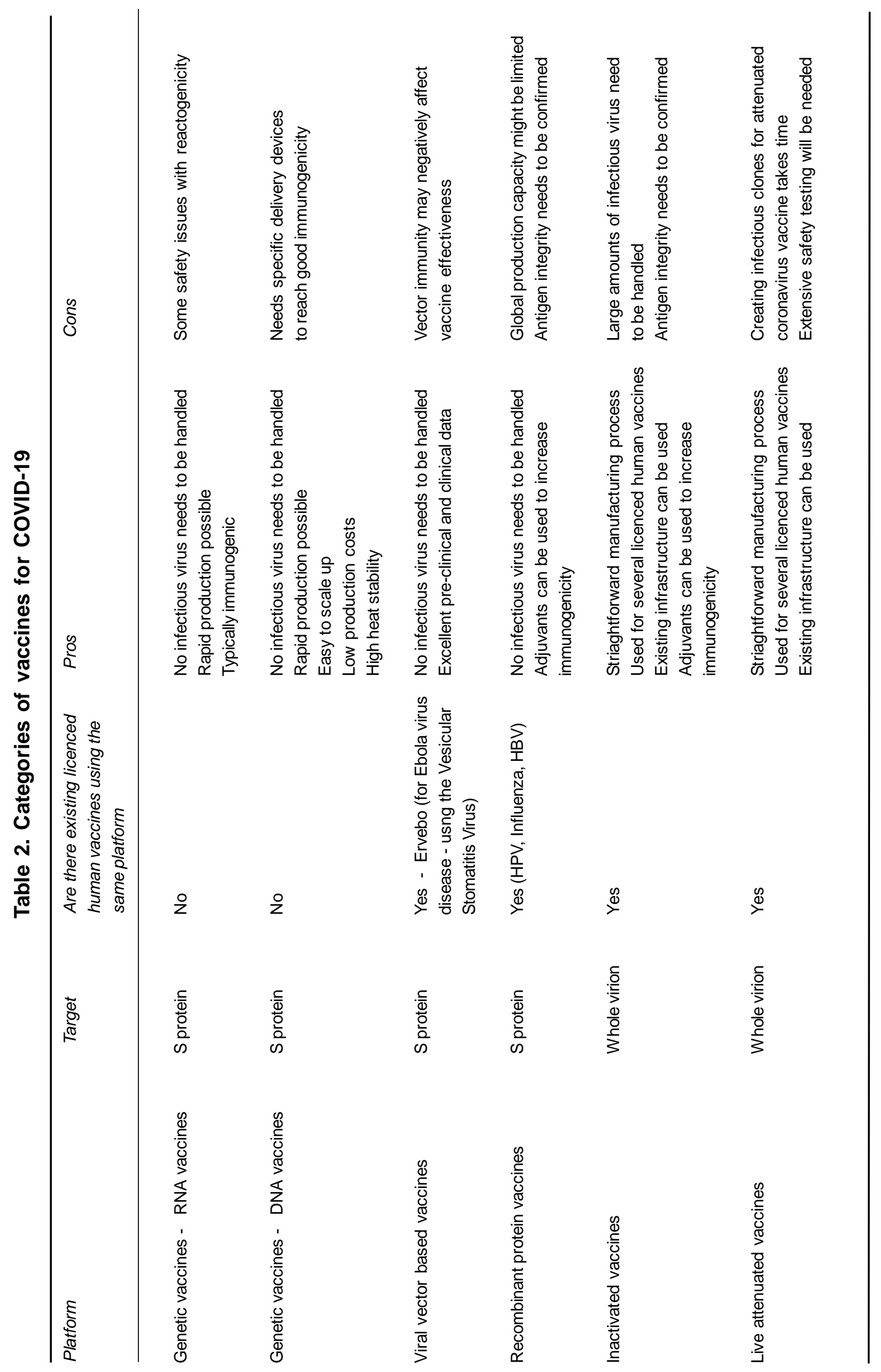


Oxford University and Astra Zeneca have developed a chimpanzee adenovirus vectored vaccine, which encodes the spike protein. ${ }^{24}$ It was found to be immunogenic and efficacious in non-human primate studies. Phase 1/2 human trials found humoral and $T$ cell responses in most recipients after the first dose of the vaccine with further boosting of the antibody responses after the second dose. A large phase 3 trial is ongoing. The Gamaleya Research Centre have developed a vaccine consisting of recombinant adenovirus serotype 26 and 5 vectors. ${ }^{25}$ A phase $1 / 2$ human trial reported seroconversion in $100 \%$ of recipients and a CD4+ and CD8+ T cell immune response in all subjects that peaked at 28 days postvaccination. Surprisingly, on August $12^{\text {th }} 2020$, this vaccine (now named Sputnik V) was granted approval for limited use in Russia, prior to the completion of the phase 3 trials. CanSino Biologics and Jonhson and Johnson have developed recombinant adenovirus 5 and adenovirus 26 vectored vaccines respectively and have ongoing phase 3 human trials. ${ }^{26-30} \mathrm{~A}$ recent update from the Oxford vaccine suggests it produces similar neutralising antibody titres and $T$ cells responses across all three age groups (18-55, 56-69 and 70+ years).

\section{Recombinant protein-based vaccines}

When recombinantly synthesised SARS-CoV-2 viral proteins or protein fragments (such as the RBD) are injected, they stimulate an immune response. This technique mainly induces a humoral immune response and needs appropriate adjuvants to increase immunogenicity. The NVX-CoV2373 nanoparticle vaccine contains recombinant full length wild-type SARS-CoV2 (rSARS-CoV-2) and the Matrix M1 adjuvant (a saponin based adjuvant). ${ }^{31}$

\section{Inactivated virus vaccines}

These vaccines require an adjuvant to boost immunogenicity. For instance, the vaccine candidate from SinoVac uses aluminium hydroxide (Alum). This induces a predominantly humoral based immune response. Other adjuvants such as monophosphoryl Lipid A (MPL) may help stimulate a cellular immune response too. Sinovac Biotech and Sinopharm are at present conducting phase 3 trials on inactivated vaccines. $^{32-34}$

\section{Trained immunity-based vaccines}

Trained immunity-based vaccines stimulate the innate immune system and provides protection to unrelated pathogens. The BCG vaccine is currently under evaluation for its ability to induce trained immunity against SARS-CoV-2.

\section{COVID-19 vaccine clinical trial findings}

Several human clinical trials have reported their phase 1 and 2 findings (a summary of their main findings are shown in Table 3). The USA, UK, Germany, Russia and China have been the leading countries carrying out these studies. The 11 human COVID-19 vaccine trials that have reported their results have included 3586 participants (range - 40 to 1192), age range: 18 to 80 years. The SARS-CoV-2 spike protein has been the vaccine target for most of the trials, whilst a group from China used whole virion as the target. Nine of the eleven were randomized trials. Some were phase 1 trials and others were combined phase $1 / 2$ or phase 2 trials. Only a few mild to moderate adverse effects were noted.

A summary of seven reported animal COVID-19 vaccine trials are shown in Table 4. Six were conducted in USA and the other in China. The US trials targeted the SARS-CoV-2 spike protein and the study from China targeted the whole virion. Mice, non-human primates, guinea pigs and hamsters were used in the studies. All the animal trials showed promising protection against COVID-19.

\section{Vaccine efficacy}

Vaccine efficacy involves the study of outcome data from randomized controlled trials (RCT) between participants that are vaccinated or not. Outcomes that may be assessed include: a reduction in infection, effect on severity of clinical disease or on duration of infectivity. ${ }^{35}$ Large scale prospective studies would help evaluate the effectiveness and immunogenicity in different strata of the population. Standardized approaches for assessing efficacy endpoints are important for making comparisons between the different vaccine candidates. Instead of measuring only clinical outcomes, validated and robust immunological correlates of protection may be used as surrogate markers. For this, properly designed in-vitro immune based assays would be needed. Reinfections have been reported in a subset of individuals thus raising the possibility of waning of long-standing immunity. Furthermore, the efficacy of antibody generating vaccines in immunocompromised or immunodeficient patients may be sub-optimal.

Controlled human challenge studies involve the exposure of human volunteers to infectious pathogens. Recently, the human challenge consortium was convened to explore the feasibility and ethics of such studies. Proponents of such studies argue they would allow rapid assessment of vaccine efficacy and thus discontinue any that are found to be ineffective. 


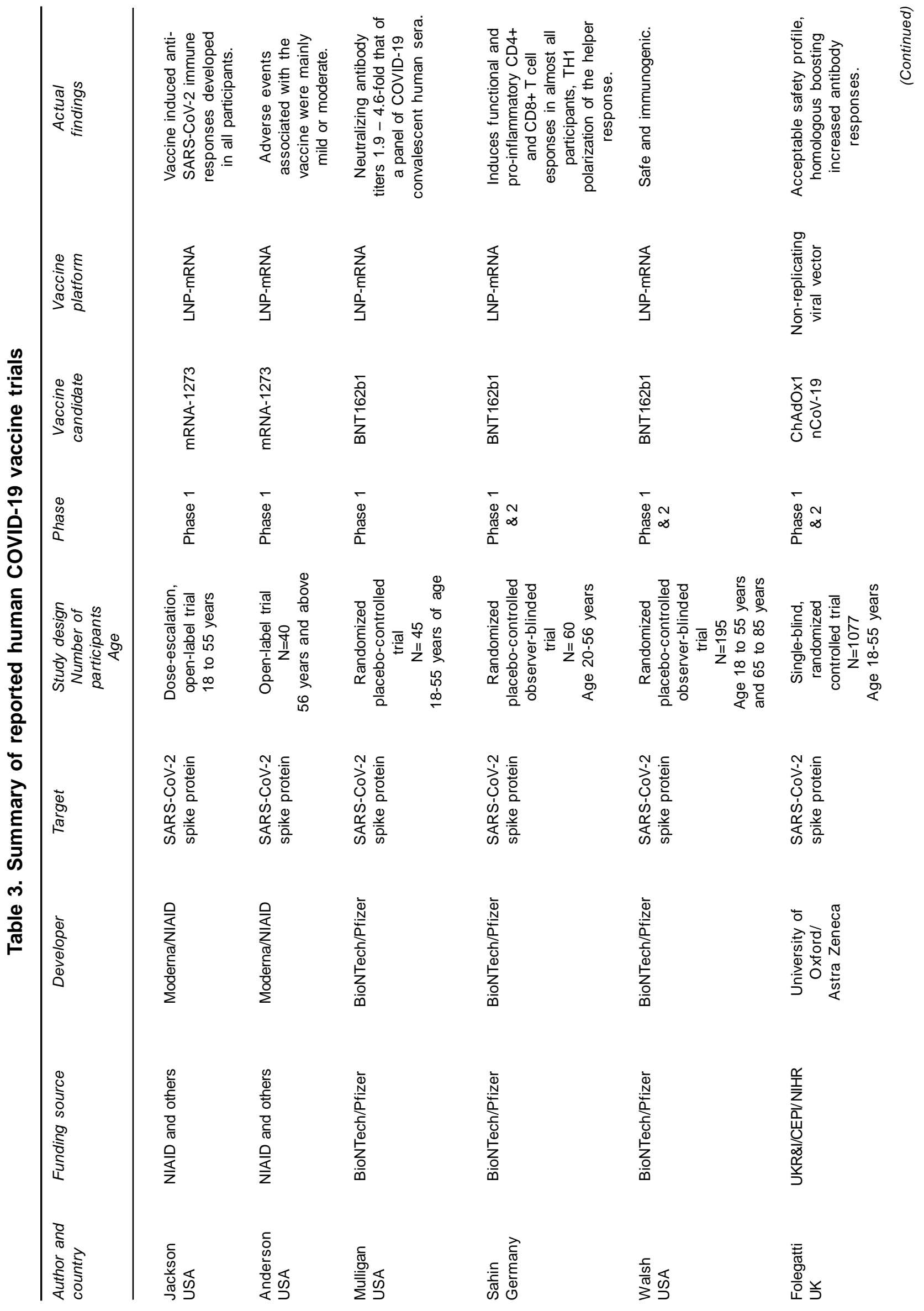




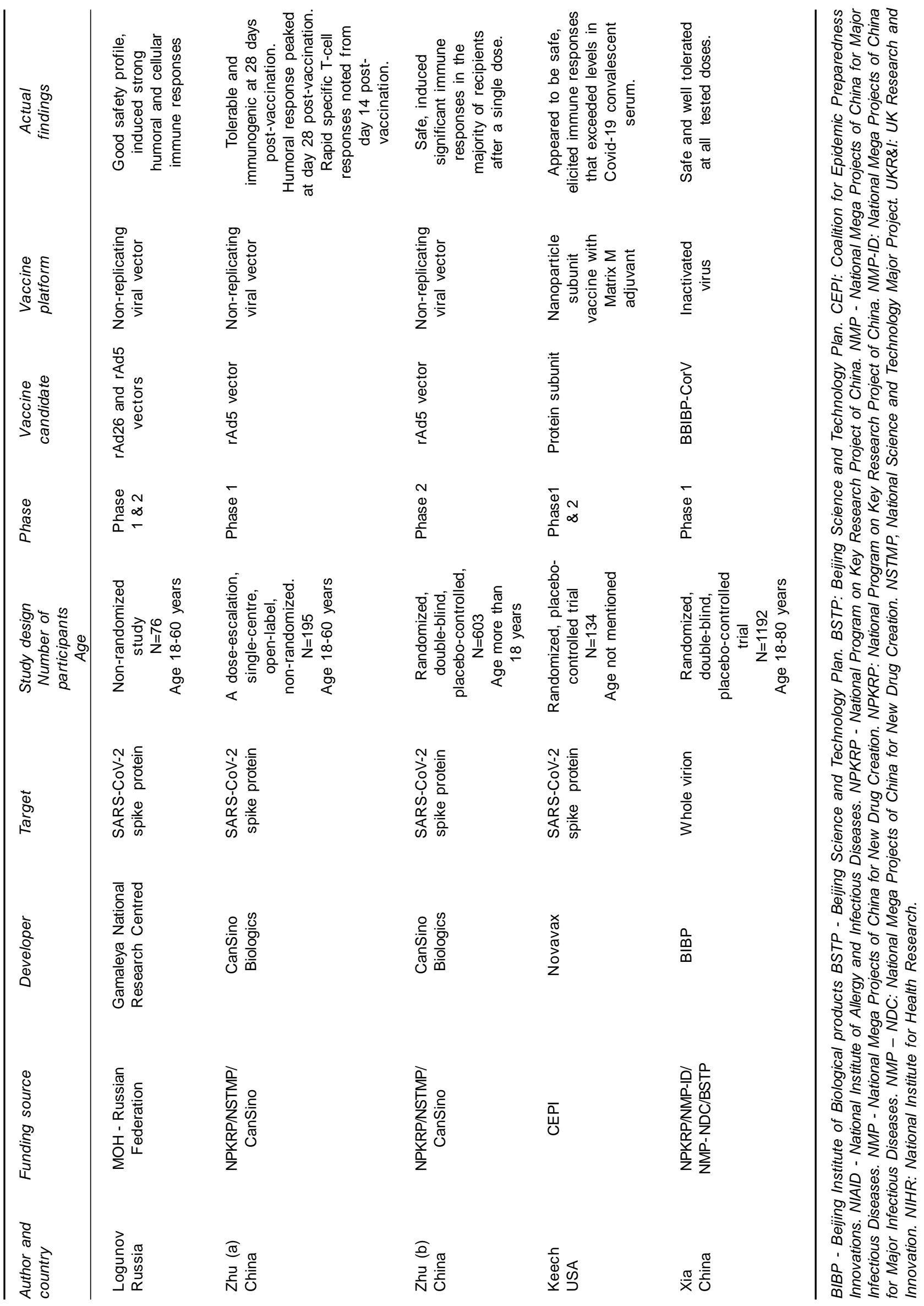




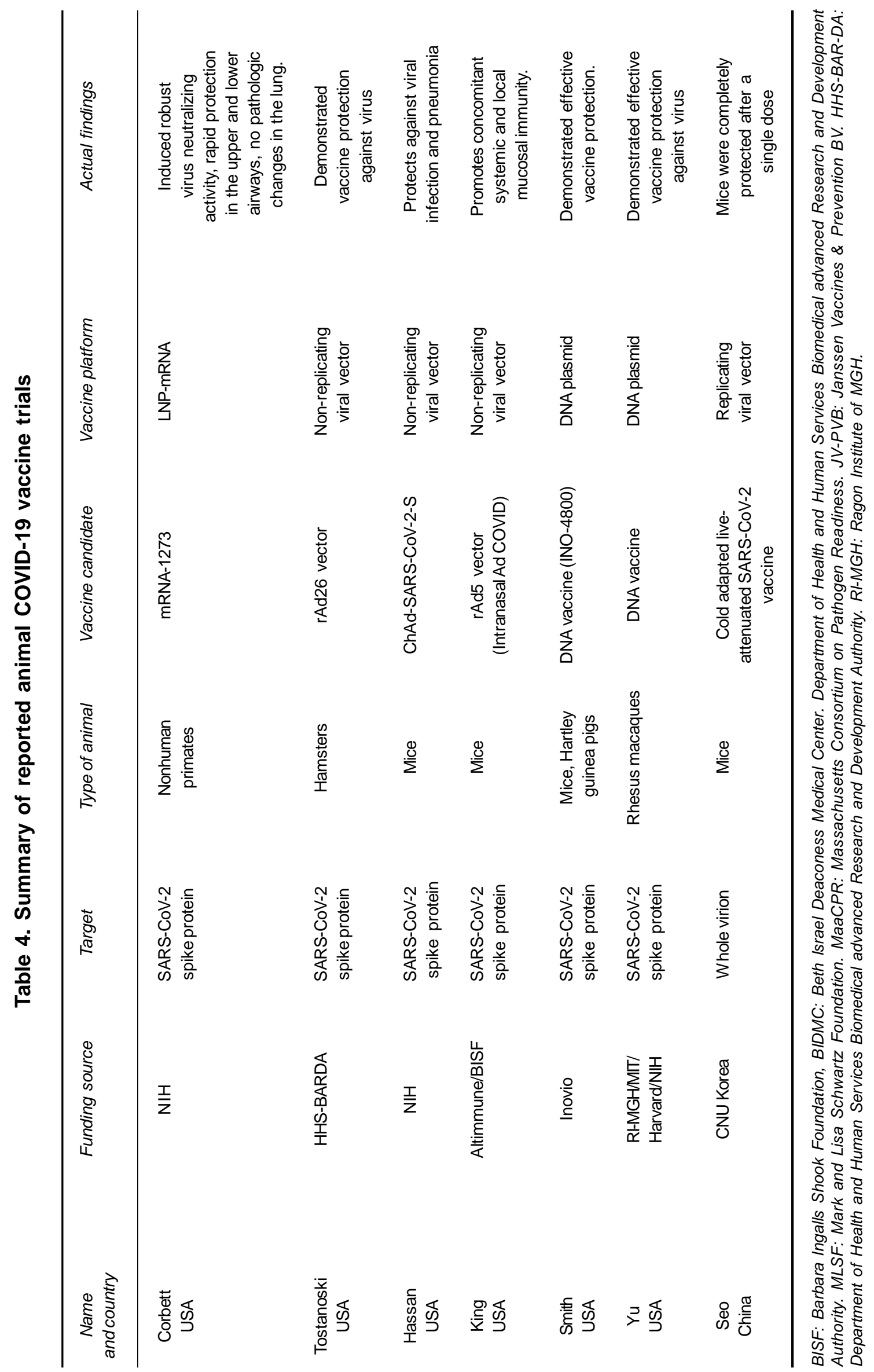


However, such studies could be logistically difficult to arrange and may involve challenging a group of young otherwise healthy individuals that really does not represent the demographic to whom the vaccine would be first targeted. However, such studies may provide important immunological insights into the disease pathogenesis in a controlled manner.

\section{Vaccine safety}

Having safe vaccines are critical for any widespread vaccination programmes. The population at large, needs to be continuously updated on the safety aspects of all the evaluated COVID-19 vaccines. Furthermore, complete transparency in the reporting of findings from the various large-scale clinical trials is essential. Assessment of vaccine safety needs to be inbuilt into all stages of clinical development of the different vaccine candidates. Furthermore, they need to continue once a vaccine has been approved for use and then given to large population groups. With COVID19 vaccines, this is especially important as some of the vaccine platforms are novel (mRNA, DNA, nanoparticle, viral vector) and thus need careful safety checks. Standardised definitions and lists of adverse effects of special interest have been discussed and agreed on. Human COVID-19 vaccine studies that have reported thus far, have shown acceptable safely profiles of the different vaccine platforms and constructs. Overall, the inactivated whole virus vaccine constructs were found to be the least reactogenic.

\section{Access to COVID-19 vaccines}

Equitable and simultaneous access to new COVID-19 vaccines is the hope for stopping the progression of the pandemic. ${ }^{36}$ Once effective COVID19 vaccines are developed and approved, questions of how to distribute them equitably across different countries would arise. Aspects relating to 'Vaccine Nationalism' should be strongly guarded against at all cost, by ensuring ethical and effective frameworks are in place for international COVID-19 vaccine allocation and distribution. Reducing premature deaths would take precedence in any COVID-19 vaccine allocation programme. It is likely that persons at greatest risk of COVID-19 (healthcare workers, nursing home residents, persons with underlying health conditions, the elderly) would be the first to be given access to a COVID-19 vaccine. COVAX is one of three pillars of the Access to COVID-19 Tools Accelerator. It is coordinated by the WHO, Global Alliance for Vaccines and Immunization (Gavi), and the Coalition for Epidemic Preparedness and Innovations (CEPI). It was set up to ensure research, purchase and distribution of any new vaccines is shared equally between the world's rich countries and developing states. Since the first useful COVID-19 vaccines would be in short supply, any approved vaccines would be targeted to $3 \%$ of the population of each of the countries in the coalition. China has recently become a partner of this coalition.

\section{Vaccine hesitancy}

COVID-19 vaccine hesitancy is an important aspect to be discussed and considered. ${ }^{37}$ Recent reports suggest between one sixth and one half of the UK population may refuse to receive a COVID-19 vaccine. ${ }^{38,39}$ This in turn would pose a serious threat to achieving widespread SARS-CoV-2 immunity.

\section{Conclusions}

The continuing COVID-19 pandemic and its adverse individual, societal and economic effects necessitate finding of effective control measures as an important and urgent global need. Effective and safe vaccines are known to reduce high disease burdens in other diseases and to have the greatest beneficial effects on a wide scale. The hope is that one or more of the presently evaluated COVID-19 vaccine candidates would prove to be safe, immunogenic and efficacious and would play its role in controlling this devastating pandemic.

\section{References}

1. Borges do Nascimento IJ, Cacic N, Abdulazeem HM, et al. Novel coronavirus infection (COVID-19) in humans: a scoping review and meta-analysis. Journal of Cinical Medicine 2020; 9(4): 941.

2. Jayasekara D, Seneviratne SL, Jayasekara A, De Zoysa I. Atypical Presentations of COVID-19. Advances in Infectious Diseases 2020; 10 (3): 136-42.

3. World Health Organization. Coronavirus disease (COVID2019) situation reports. 2020.

4. Rahman A, Niloofa R, De Zoysa IM, Cooray AD, Kariyawasam $J$, Seneviratne SL. Neurological manifestations in COVID19: A narrative review. SAGE Open Med. 2020; 8: https:// doi.org/10.1177/2050312120957925.

5. De Zoysa IM, Seneviratne SL, Abeysuriya V. Surgical Implications of COVID-19. Int J Prog Sci \& Tech. 2020; 21: $130-3$.

6. Jayasinghe R, Jayarajah $U$, Seneviratne $S$. Consensus on peri-operative surgical practice during the COVID-19 pandemic: an appraisal of the literature. Sri Lanka Journal of Surgery 2020; 38(2): 57-61.

7. Borges do Nascimento IJ, von Groote TC, O'Mathúna DP, et al. Clinical, laboratory and radiological characteristics and outcomes of novel coronavirus (SARS-CoV-2) infection in humans: A systematic review and series of meta-analyses. PloS One 2020; 15(9): e0239235. 
8. Niloofa R, Seneviratne S, Cooray A, Senanayake NP, De Zoysa I. Molecular Diagnosis of COVID-19. Int J Prog Sci \& Tech. 2020; 20: 33-6.

9. Seneviratne SL, Abeysuriya V, de Mel S, De Zoysa I, Niloofa R. Favipiravir in COVID-19. Int J Prog Sci \& Tech. 2020; 19: $143-5$.

10. Seneviratne SL, Niloofa R, De Zoysa I, de Mel S, Abeysuriya V. Remdesivir and COVID-19. Int. J. Adv. Res. 2020; 8(04): 565-567

11. Wrapp D, Wang N, Corbett KS, et al. Cryo-EM structure of the 2019-nCoV spike in the prefusion conformation. Science 2020; 367: 1260-3.

12. Rausch JW, CapoferriAA, Katusiime MG, Patro SC, Kearney MF. Low genetic diversity may be an Achilles heel of SARSCoV-2. Proc Natl Acad Sci U S A. 2020; 117(40): 24614-16.

13. Kames J, Holcomb DD, Kimchi O, et al. Sequence analysis of SARS-CoV-2 genome reveals features important for vaccine design. Sci Rep. 2020; 10(1): 15643.

14. Jackson LA, Anderson EJ, Rouphael NG, et al. An mRNA vaccine against SARS-CoV-2 - preliminary report. $N$ Engl $J$ Med. 2020; 383: 1290 -1931.

15. Anderson EJ, Rouphael NG, Widge AT, et al. Safety and Immunogenicity of SARS-CoV-2 mRNA-1273 Vaccine in Older Adults. N Engl J Med. 2020 Sep 29. DOI: 10.1056/ NEJMoa2028436

16. Mulligan MJ, Lyke KE, Kitchin N, Absalon J, Gurtman A, Lockhart $S$ et al. Phase I/II study of COVID-19 RNA vaccine BNT162b1 in adults. Nature 2020; 586(7830): 589-93.

17. Sahin U, Muik A, Derhovanessian E, et al. COVID-19 vaccine BNT162b1 elicits human antibody and $\mathrm{T}(\mathrm{H}) 1 \mathrm{~T}$ cell responses. Nature. 2020; 586(7830): 594-9.

18. Walsh EE, Frenck RW Jr, Falsey AR, et al. Safety and Immunogenicity of Two RNA-Based Covid-19 Vaccine Candidates. N Engl J Med. 2020 Oct 14. DOI: 10.1056/ NEJMoa2027906

19. Corbett KS, Flynn B, Foulds KE, et al. Evaluation of the mRNA1273 Vaccine against SARS-CoV-2 in Nonhuman Primates. N Engl J Med. 2020; 383(16): 1544-55.

20. Gallager J. Covid vaccine: First 'milestone' vaccine offers 90\% protection. BBC News 09th Nov 2020.

21. Mason J, Guarascio F, Erman M, Burger L, BanerjeeA, Smout A. Instant View: Moderna says its vaccine is $94.5 \%$ effective in preventing COVID-19. Reuters 16th Nov 2020.

22. Smith TRF, Patel A, Ramos S, et al. Immunogenicity of a DNA vaccine candidate for COVID-19. Nat Commun 2020; 11: 2601.

23. Yu J, Tostanoski LH, Peter L, et al. DNA vaccine protection against SARSCoV-2 in rhesus macaques. Science 2020; 369(6505): 806-811. doi:10.1126/science.abc6284
24. Folegatti PM, Ewer KJ, Aley PK, et al. Safety and immunogenicity of the ChAdOx $1 \mathrm{nCoV}-19$ vaccine against SARS-CoV-2: a preliminary report of a phase $1 / 2$, singleblind, randomised controlled trial. Lancet 2020; 396: 467-78.

25. Logunov DY, Dolzhikova IV, Zubkova OV, et al. Safety and immunogenicity of an rAd26 and rAd5 vector-based heterologous prime-boost COVID-19 vaccine in two formulations: two open, non-randomised phase 1/2 studies from Russia. Lancet 2020; 396(10255): 887-97.

26. Hassan AO, Kafai NM, Dmitriev IP, et al. A Single-Dose Intranasal ChAd Vaccine Protects Upper and Lower Respiratory Tracts against SARS-CoV-2. Cell 2020; 183(1): 169-84.

27. Zhu F-C, Li Y-H, Guan X-H, et al. Safety, tolerability, and immunogenicity of a recombinant adenovirus type- 5 vectored COVID-19 vaccine: a dose-escalation, open label, nonrandomised, first-in-human trial. Lancet 2020; 395: 1845-54.

28. Zhu FC, Guan XH, Li YH, et al. Immunogenicity and safety of a recombinant adenovirus type-5-vectored COVID-19 vaccine in healthy adults aged 18 years or older: a randomised, double-blind, placebo-controlled, phase 2 trial. Lancet 2020 ; 396(10249): 479-488.

29. King RG, Silva-Sanchez A, Peel JN, et al. Single-dose intranasal administration of AdCOVID elicits systemic and mucosal immunity against SARS-CoV-2 in mice. bioRxiv. 2020 Oct 11. doi: https://doi.org/10.1101/2020.10.10.331348

30. Tostanoski LH, Wegmann F, Martinot AJ, et al. Ad26 vaccine protects against SARS-CoV-2 severe clinical disease in hamsters. Nat Med. 2020. https://doi.org/10.1038/s41591020-1070-6

31. Keech Cl, Albert G, Cho I, S et al. Phase 1-2 Trial of a SARSCoV-2 Recombinant Spike Protein Nanoparticle Vaccine. $N$ Engl J Med. 2020; Sep 2. DOI: 10.1056/NEJMoa2026920

32. Xia S, Zhang $Y$, Wang $Y$, et al. Safety and immunogenicity of an inactivated SARS-CoV-2 vaccine, BBIBP-CorV: a randomised, double-blind, placebo-controlled, phase 1/2 trial. Lancet Infect Dis. 2020 Oct 15:S1473-3099(20)30831-8.

33. Palacios R, Patiño EG, de Oliveira Piorelli R, et al. DoubleBlind, Randomized, Placebo-Controlled Phase III Clinical Trial to Evaluate the Efficacy and Safety of treating Healthcare Professionals with the Adsorbed COVID-19 (Inactivated) Vaccine Manufactured by Sinovac - PROFISCOV: A structured summary of a study protocol for a randomised controlled trial. Trials 2020; 21(1): 853.

34. Seo SH, Jang Y. Cold-Adapted Live Attenuated SARS-Cov2 Vaccine Completely Protects Human ACE2 Transgenic Mice from SARS-Cov-2 Infection. Vaccines (Basel). 2020; 8(4): https://doi.org/10.3390/vaccines8040584. 
35. Hodgson SH, Mansatta K, Mallett G, et al. What defines an efficacious COVID-19 vaccine? A review of the challenges assessing the clinical efficacy of vaccines against SARSCoV-2. Lancet Infect Dis. Epub ahead of print 2020. DOI: 10.1016/S1473-3099(20)30773-8.

36. Gayle H, Foege W, Brown L, et al. Framework for Equitable Allocation of COVID-19 Vaccine. Washington (DC): National Academies Press (US); 2020 Oct 2.

37. Jayasinghe R, Ranasinghe S, Jayarajah $U$, Seneviratne S. Quality of online information for the general public on
COVID-19. Patient Education and Counseling 2020; 103(12): 2594-7.

38. Lazarus JV, Ratzan SC, PalayewA, et al. A global survey of potential acceptance of a COVID-19 vaccine. Nat Med. 2020: 20: 1-4.

39. Kreps S, Prasad S, Brownstein JS, Hswen Y, Garibaldi BT, Zhang B, Kriner DL. Factors Associated With US Adults' Likelihood of Accepting COVID-19 Vaccination. JAMA Netw Open. 2020; 3(10):e2025594. 